\title{
Energia de briquetes produzidos com rejeitos de resíduos sólidos urbanos e madeira de Eucalyptus grandis
}

\author{
José E. Gonçalves ${ }^{1}$, Maria M. P. Sartori ${ }^{2} \&$ Alcides L. Leão ${ }^{1}$
}

\begin{abstract}
RESUMO
O incentivo ao consumo e à produção em grande quantidade na sociedade atual gera, exageros de resíduos sólidos urbanos que, em alguns casos, podem ser utilizados para a geração de energia. Neste sentido e visando reduzir os resíduos dos aterros municipais e gerar energia, buscou-se produzir briquetes com mistura de rejeitos de resíduos sólidos urbanos (RRSU) e resíduos de madeira de Eucalyptus grandis. Os briquetes foram fabricados com 0, 5, 10, 15, 20 e $25 \%$ de RRSU na mistura com resíduos madeireiros contendo $12 \%$ de umidade. Os parâmetros analisados para a escolha da melhor mistura, foram: análise de combustibilidade x cinzas, resistência e energia utilizável. Os briquetes com até $10 \%$ de RRSU se mostraram com baixa resistência e os acima de 15\% apresentaram grande aumento no teor de cinzas; portanto, os que melhor atenderam aos requisitos combustibilidade x cinzas e resistência mecânica, foram aqueles com $15 \%$ de RRSU, pois não se conhece a procedência das cinzas. Considerando-se a energia utilizável, o briquete com $25 \%$ de RRSU é o que apresenta maior poder calorífico útil na ordem de $17.175 \mathrm{~kJ} \mathrm{~kg}^{-1}$ motivo pelo qual se indica a produção de briquetes com adição RRSU; ressalta-se, porém, a necessidade de estudos sobre a emissão de gases.
\end{abstract}

Palavras-chave: biomassa, lixo, poder calorífico

\section{Energy from briquettes produced from remains of urban solid residues and wood of Eucalyptus grandis}

\begin{abstract}
The incentive for consumption and production in large quantity in modern society generates enormous amounts of urban solid residues in the form of municipal solid waste (MSW). With the intention of reducing these residues of the municipal waste tips and to generate energy, briquettes with mixtures of MSW and residues of Eucalyptus grandis were produced. The briquettes were manufactured with $0,5,10,15,20$ and $25 \%$ of MSW in the mixture with wood waste and $12 \%$ of moisture content. The analyzed parameters used to choose the best treatments were combustion analysis versus ash content, mechanical strength and energy content. The briquettes up to 10\% of MSW showed low resistance, and above 15\% showed large increase in ash content. Therefore, the treatment that fulfilled the requirements for combustion versus ash content and mechanical resistance was of at least $15 \%$ of MSW, since the source of the ash is unidentified. Considering the net energy content, the best treatment was $25 \%$ of MSW, with $17,175 \mathrm{~kJ} \mathrm{~kg}^{-1}$. Nevertheless, it is strongly advised that further studies related to gas emissions are necessary.
\end{abstract}

Key words: biomass, trash, calorific power

${ }^{1}$ Departamento de Ciências Ambientais/UNESP, Fazenda Lageado s/n. CP 237, CEP 18610-307, Botucatu, SP. Fone: (14) 3811-7162. E-mails: evaristo@ fca.unesp.br; alcidesleao@fca.unesp.br

2 Departamento de Engenharia de Produção/UNESP, Av. Eng. Luiz Edmundo C. Coube 14-01. CEP 17033-360, Bauru, SP. Fone: (14) 3815-7932. E-mail: msartori@btu.flash.tv.br 


\section{INTRODUÇÃO}

O desenvolvimento de um país está diretamente relacionado ao aumento do consumo energético e, conseqüentemente, ao crescimento da geração de lixo urbano por habitante. O lixo se torna problema quando a capacidade de tratamento adequado é ultrapassada (Jardim \& Wells, 1995), ou seja, produzir lixo além da capacidade de tratamento se torna condição insustentável (Kanayama, 1995).

Todo e qualquer tipo de lixo produzido nas cidades, proveniente de atividades humanas e que são lançados no ambiente, é classificado Resíduos Sólidos Urbanos ou municipais (RSU). A composição desses resíduos pode variar conforme as características de cada cidade (Calderoni, 1997).

Em 1995 o Brasil produzia 241.614 t de lixo por dia e 76\% ficavam expostos a céu aberto, em lixões; hoje, a produção brasileira de lixo "per capita" gira em torno de $600 \mathrm{~g} \mathrm{hab}^{-1} \mathrm{dia}^{-1}$ com a existência de poucos aterros sanitários ou aterros controlados para esta demanda (CEMPRE, 2005).

Estima-se que em São Paulo cada habitante produz $1 \mathrm{~kg}$ de lixo por dia e este valor tende a crescer, tornando a problemática do lixo inexorável e irreversível legitimando, assim, a necessidade de alternativas eficazes e custo-efetivo para o destino do lixo na Grande São Paulo (CEMPRE, 2005).

O estímulo ao consumo e à produção em larga escala na sociedade atual, gera grandes quantidades de RSU, dente os quais se encontram os Rejeitos de Resíduos Sólidos Urbanos (RRSU) em diversos setores do mercado, cujo destino diz respeito aos aterros municipais (Tillman et al., 1989).

Os RRSU são misturas complexas de compostos orgânicos, polímeros artificiais, produtos de celulose, inorgânicos; esta complexidade torna difícil sua reciclagem para a produção de energia pelo fato de seus insumos químicos serem poluentes. Desta forma, a briquetagem, que segundo Quirino (1991), é um processo no qual os materiais são densificados concentrando energia e diminuindo significativamente o volume, é uma possível solução para o problema.

É possível economizar energia com gerenciamento integrado de Resíduos Sólidos Urbanos, conservando aquela decorrente da redução do consumo, reutilizando ou usando materiais recicláveis no processo de produção, através da queima de resíduos. Segundo Gripp (1998), o RRSU pode ser reduzido, reutilizado e, principalmente, reciclado.

A indústria madeireira tem a característica de gerar grandes volumes de resíduos no processo de beneficiamento de madeira. Esta geração ocorre nos processos normais ou mesmo antes da madeira ser introduzida no processo propriamente dito, por não atenderem às exigências do mercado consumidor, tornando-se resíduo, juntamente com as serragens, maravalhas, costaneiras, aparas, pó de serra etc. (Pereira Júnior, 2001). Atualmente, esses resíduos são procurados por granjas mas a oferta de serragem ainda supera, em muito, a procura, e o material muitas vezes não tem finalidade específica. A vantagem de se utilizar a serragem na forma de briquetes consiste em um gerenciamento sustentável desses resíduos como forma de gerar energia em volumes compactos a partir de um recurso natural renovável, além de não possuir caráter poluidor de fontes fósseis de energia (Acioli, 1994).
Na geração de energia a partir da biomassa, um parâmetro que deve ser controlado é o teor de umidade uma vez que, quanto menor o teor de umidade maior será a produção de calor por unidade de massa (Vale et al., 2000), haja vista que a presença de água representa poder calorífico negativo, pois parte da energia liberada é gasta na vaporização da água e se o teor de umidade for muito variável, poderá dificultar o processo de combustão, havendo necessidade de constantes ajustes no sistema (Brito, 1986). Neste sentido, Farinhaque (1981) sugere um teor de umidade de $20 \%$ para a queima, visto que os valores superiores reduzem o valor do calor de combustão, a temperatura da câmara de queima e a temperatura dos gases de escape.

Avalia-se, neste trabalho, a produção de briquetes com mistura de rejeitos de resíduos sólidos urbanos (RRSU) e resíduos madeireiros Eucalyptus grandis e seu uso para a geração de energia.

\section{MATERIAL E MÉTODOS}

\section{Acondicionamento e seleção dos materiais componentes das amostras dos RRSU}

Uma amostra de $90 \mathrm{~kg}$ de RRSU foi coletada na esteira da Usina de Reciclagem e Compostagem de Lixo do Município de Lençóis Paulista e sua composição, quanto à natureza (termoplásticos, termofixos, borrachas, celulose, vidros, metais entulhos, madeira, tecidos e orgânicos) foi expressa em função da porcentagem em peso de cada componente (fração) em relação à massa total de resíduos.

Os polímeros presentes na amostra foram classificados segundo a composição química, devido às suas diferentes características e selecionados para a produção dos briquetes, os termoplásticos e a celulose que, por terem muitas impurezas aderidas e/ou tamanho diminuto, não foram destinados à reciclagem. A mistura de celulose e termoplásticos foi moída, de modo que o tamanho das partículas ficasse compreendido entre 5 e $10 \mathrm{~mm}$ de espessura.

Fez-se a análise do teor de umidade da mistura sem que esta passasse por qualquer forma de tratamento ou secagem, desde o momento da coleta.

\section{Resíduos de serragem de eucalipto}

Coletaram-se $150 \mathrm{~kg}$ de resíduos madeireiros, na forma de serragem, proveniente do beneficiamento de Eucalyptus grandis. O material foi moído de modo que a granulometria de suas partículas estivesse entre 5 e $10 \mathrm{~mm}$ de espessura.

\section{Método para a preparação dos compósitos e briquetagem}

Segundo Sartori et al. (2001) o preparo dos compósitos foi iniciado pela trituração dos resíduos utilizando-se um aparelho de Marca: Seibt, modelo: M6HS 6/230, RPM: 1720, $\mathrm{n}^{\circ}$ de série: $24.183 \mathrm{~B}$, ajustado para produzir partículas com granulometria entre 5 e $10 \mathrm{~mm}$.

Para o processo de briquetagem é conveniente que as partículas estejam com teor de umidade compreendido entre $10 \mathrm{e}$ 15\%; para a redução da umidade das amostras de RRSU e da serragem de eucalipto, utilizou-se de uma estufa de ventilação 
forçada a $105^{\circ} \mathrm{C}$, por um período de tempo suficiente para que o material atingisse o teor de umidade desejado.

Utilizou-se, para o cálculo, a seguinte expressão:

$$
\mathrm{U}=\frac{\mathrm{M}_{\mathrm{u}}-\mathrm{M}_{\mathrm{s}}}{\mathrm{M}_{\mathrm{m}}} 100
$$

donde:

$$
\begin{aligned}
& \mathrm{Mu} \text { - massa úmida, g } \\
& \mathrm{Ms} \text { - massa secada a } 0 \% \text { de umidade, } \mathrm{g} \\
& \mathrm{U} \text { - teor de umidade em base úmida, \% }
\end{aligned}
$$

O RRSU (termoplásticos + celulose) e a madeira moídos foram misturados nas proporções propostas para a briquetagem, apresentadas na Tabela 1.

Tabela 1. Plano de ensaios de briquetes em função da composição percentual de resíduos sólidos urbanos e madeireiros

\begin{tabular}{ccc}
\hline Ensaio & \% de Resíduos Madeireiros & $\begin{array}{c}\text { \% de RRSU } \\
\text { (termoplásticos + celulose) }\end{array}$ \\
1 & 95 & 5 \\
2 & 90 & 10 \\
3 & 85 & 15 \\
4 & 80 & 20 \\
5 & 75 & 25 \\
\hline
\end{tabular}

Em nenhum ensaio se deu a adição de material aglutinante, pois a temperatura dentro da caixa do pistão a $250{ }^{\circ} \mathrm{C}$ faz com que as moléculas de lignina, ao serem fluidizadas, se transformem em produtos com características aglutinantes; por outro lado, as amostras com diferentes teores de madeira e RRSU foram briquetados com umidade aproximada em 12\% em uma briquetadeira Modelo Biomax b-95/210, motor $75 \mathrm{cv}$ a uma pressão de 1 tonelada distribuída em $12 \mathrm{~cm}$ de diâmetro na entrada da caixa do pistão que, juntamente com intenso atrito, eleva a temperatura para $250{ }^{\circ} \mathrm{C}$, fluidificando-a. O produto sai do aparelho em formato de corda, e é dividido em briquetes de $30 \mathrm{~cm}$ de comprimento por $8 \mathrm{~cm}$ de diâmetro.

\section{Método para análise do teor de combustíveis e teor de cinzas}

A determinação dessas propriedades é imprescindível para a caracterização dos resíduos. O teor de combustíveis e o teor de cinzas (ou inertes) fornecem informações aproximadas da combustibilidade dos resíduos e, segundo o Guia de Prática de Análise Imediata de Combustíveis Sólidos - UFMG, é obtido através do seguinte procedimento: tritura-se cada elemento componente dos resíduos (papel, plástico etc.) separadamente; as partes obtidas são misturadas mantendo-se a proporcionalidade em massa e só então se acrescentam os resíduos madeireiros na proporção adequada para a briquetagem; retira-se uma amostra de $10 \mathrm{~g}$, que é colocada em um cadinho de porcelana e secada a $105^{\circ} \mathrm{C}$, durante quatro horas; após esfriar a amostra deve ser pesada e só então carbonizada em cadinho de porcelana a $800^{\circ} \mathrm{C}$, pelo tempo de duas horas, na mufla; depois de esfria ela é pesada novamente (Gomes, 1980).
O teor de combustíveis (TC) é calculado pela equação abaixo:

$$
\mathrm{TC}=(\mathrm{c}-\mathrm{d}) / \mathrm{c} \times 100,
$$

donde:

$$
\begin{gathered}
\text { TC - teor de combustíveis, \% } \\
\text { c - peso antes da queima, g } \\
\text { d - peso após a queima, g }
\end{gathered}
$$

O teor de cinzas é obtido por:

$$
\mathrm{TCZ}=100-\mathrm{TU}-\mathrm{TC},
$$

donde:

$$
\begin{aligned}
& \text { TCZ - teor de cinzas, \% } \\
& \text { TU - teor de umidade, \% } \\
& \text { TC - teor de combustíveis }
\end{aligned}
$$

\section{Método para análise elementar dos briquetes}

Para a realização da análise elementar, retiraram-se $2 \mathrm{~g}$ de amostra de briquete considerando-se cada ensaio; este material foi enviado à Central Analítica do Instituto de Química da USP, onde se determinaram os teores de carbono, hidrogênio e nitrogênio presentes nas amostras.

A porcentagem de hidrogênio de cada amostra foi utilizada para o cálculo do poder calorífico inferior (PCI).

\section{Método para determinação do poder calorífico superior (PCS)}

As amostras utilizadas para análise do PCS foram moídas, secadas e peneiradas em peneira ABNT 70, segundo a norma ABNT - NBR 8633 e prensadas na forma de pastilhas com aproximadamente $1 \mathrm{~g}$ cada uma; depois, foram levadas à estufa a $105^{\circ} \mathrm{C}$ até a estabilização do peso, indicando que a amostra está seca. Após este procedimento, as amostras foram novamente pesadas e queimadas em bomba calorimétrica ALEMMAR, modelo KL-5, cuja a metodologia para obtenção do poder calorífico superior foi baseada no Manual de Instruções do Calorímetro e adaptada de acordo com a norma ABNT-NBR 8633.

De cada ensaio com diferentes teores de celulose e termoplásticos + madeira foram analisadas cinco amostras escolhidas aleatóriamente para obtenção de PCS médio de cada blenda (Doat, 1977):

\section{Método para determinação do poder calorífico inferior (PCI) e poder calorífico útil dos briquetes (PCU)}

O poder calorífico inferior (PCI) e o poder calorífico útil (PCU), foram definidos, segundo Brito (1993), conforme utilizado por Sartori \& Leão (2002) atendendo às fórmulas descritas a seguir; o teor de umidade do material foi mantido a 0\% para o cálculo do PCI e a 12\% para o cálculo do PCU.

$$
\mathrm{PCI}=\mathrm{PCS}-600(9 \mathrm{H} / 100) \quad \mathrm{PCU}=\mathrm{PCI}(1-\mathrm{u})-600 \mathrm{u}
$$

donde:

$$
\begin{aligned}
& \text { PCS - poder calorífico superior, cal g-1 } \\
& \text { PCI - poder calorífico inferior, cal g-1 }
\end{aligned}
$$




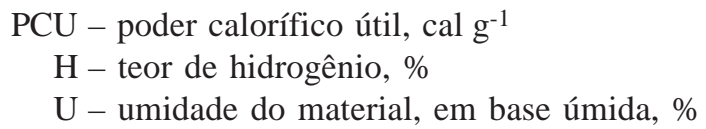

\section{Análise estatística}

Os poderes caloríficos dos briquetes foram submetidos a análise de variância (ANOVA), considerando-se os 5 tratamentos com 5 repetições e quando necessário complementados pelo teste de Tukey.

\section{RESULTADOS E DISCUSSÃO}

\section{Coleta e classificação do Rejeito de Resíduos Sólidos Urbanos (RRSU)}

A proporção dos componentes encontrados na amostra de 90 kg de RRSU está representada na Tabela 2, pode-se observar que $43,80 \%$ do material são derivados de celulose, sendo o mais abundante na amostra, seguido do material orgânico com 27,88\%; no entanto, os materiais orgânicos não foram utilizados no processo de briquetagem devido ao alto teor de umidade o que demandaria maior tempo de secagem do material e, conseqüentemente, encareceria o processo.

Tabela 2. Composição da amostra de 90 kg de RRSU

\begin{tabular}{|c|c|c|c|}
\hline Material & Exemplos encontrados & Peso (kg) & $\%$ do Total \\
\hline Derivados de Celulose & $\begin{array}{l}\text { Papel oficio, papel higiênico, jornais, } \\
\text { folders, revistas, etc. }\end{array}$ & 39,192 & 43,80 \\
\hline Termoplásticos & $\begin{array}{l}\text { Copos plásticos, sacolas e saquinhos, } \\
\text { embalagens de iogurtes, peças } \\
\text { automotivas, embalagens de frios e } \\
\text { salgados. }\end{array}$ & 14,763 & 16,50 \\
\hline *Elastômeros & $\begin{array}{l}\text { Pedaços de borrachas, luvas e } \\
\text { mangueiras }\end{array}$ & 0,765 & 0,85 \\
\hline *Termofixos & Peças automotivas & 1,335 & 1,49 \\
\hline *Vidros & Garrafas e vasilhames & 1,395 & 1,56 \\
\hline *Metais & Alumínio e aço inoxidável & 1,125 & 1,26 \\
\hline *Entulhos & Restos de material de construção & 1,965 & 2,20 \\
\hline *Madeira & Tábuas e tacos & 2,475 & 2,77 \\
\hline${ }^{*}$ Tecidos & Tecidos de algodão e sintéticos & 2,040 & 2,28 \\
\hline *Orgânicos & Restos de vegetais, carnes, grãos & 24,94 & 27,88 \\
\hline Total & & 90,00 & 100,00 \\
\hline
\end{tabular}

* Materiais que não serão utilizados no processo de briquetagem

\section{O produto (briquete)}

Os briquetes produzidos com 10 e 5\% de RRSU, para as condições experimentais deste trabalho, não apresentaram forma definida, isto é, não aglutinoram completamente.

\section{Análises físico-químicas}

Teor de cinzas e combustíveis. O teor de combustíveis é um índice importante para a briquetagem, pois indica a porcentagem de materiais com potencial de geração de calor e o teor de cinzas corresponde à porcentagem de material inerte, que não produz calor.

Visto ser desejável que após a queima dos briquetes haja a menor quantidade de cinzas, verificou-se que briquetes com menores porcentagens de RRSU resultam em menor quantidade deste componente após a queima, ou seja, possuem maior teor de combustíveis em relação aos outros briquetes com percentual maior de RRSU.

$\mathrm{O}$ teor de cinzas foi crescente sempre que se aumenta o percentual de RRSU adicionado à composição do briquete e, conseqüentemente, o inverso ocorre em relação ao teor de combustíveis. Para os ensaios se propuseram porcentagens de RRSU compreendidas entre 5 e $25 \%$ e como pode ser observado pela Tabela 3 os teores de combustíveis variaram em uma faixa entre 98,19 e 93,80\%.

Tabela 3. Teor de cinzas e teor de combustíveis dos briquetes

\begin{tabular}{cccc}
\hline \% de Madeira & \% de RRSU & $\begin{array}{c}\text { Teor de cinzas } \\
\mathbf{( \% )}\end{array}$ & $\begin{array}{c}\text { Teor de Combustiveis } \\
\mathbf{( \% )}\end{array}$ \\
95 & 5 & 1,81 & 98,19 \\
90 & 10 & 3,18 & 96,82 \\
85 & 15 & 3,30 & 96,70 \\
80 & 20 & 4,31 & 95,69 \\
75 & 25 & 6,19 & 93,81 \\
0 & 100 & 7,79 & 92,21 \\
\hline
\end{tabular}

O fato do teor de cinzas aumentar a medida em que aumenta a porcentagem de RRSU, pode estar associado a grande quantidade de impurezas aderidas ao RRSU, tais como terra e outros materiais inertes.

Os briquetes com menores quantidades de cinza foram aqueles com 5, 10 e 15\% de RRSU, ressaltando-se que o teor de cinzas tem um aumento mais significativo para os briquetes com RRSU acima de 15\% (aumento mínimo de $43,7 \%$ ), mostrando a necessidade de se verificar a procedência desse rejeito.

Nota-se que o comportamento do teor de cinzas é inversamente proporcional ao encontrado para o teor de combustíveis; neste sentido, os briquetes que apresentaram maior combustibilidade e menor teor de cinzas foram aqueles provenientes das misturas com 5, 10 e 15\% de RRSU.

Para que o briquete seja um produto competitivo no mercado, é oportuno que seu poder calorífico esteja dentro dos padrões desejados para as finalidades às quais ele se destina, seja em caldeiras, fornalhas ou na geração de eletricidade; para tanto, é conveniente atentar para a quantidade de RRSU adicionada à sua composição para que não haja comprometimento da geração de calor pela queima do briquete devido à diminuição em seu teor de combustíveis.

Poderes caloríficos. Observa-se que o poder calorífico superior médio do briquete com $25 \%$ de RRSU e $75 \%$ de madeira de eucalipto, foi de $21.239,13 \mathrm{~kJ} \mathrm{~kg}^{-1}$, acima do poder calorífico superior médio da madeira, que foi de $19.544,20 \mathrm{~kJ} \mathrm{~kg}^{-1}$, porém menor que o poder calorífico superior médio dos termoplásticos, que está na casa dos $34000 \mathrm{~kJ} \mathrm{~kg}^{-1}$ (Tabela 4).

Nota-se que, dos materiais utilizados nos ensaios de briquetagem, os termoplásticos têm um PCS maior quando comparados com os outros materiais apresentados na Tabela 4, pelo fato desses polímeros serem derivados de petróleo.

O termoplástico, composto rico no elemento carbono, é maioria na amostra, que é o responsável pela elevação do PCS do briquete, na medida em que aumenta a sua proporção, 
conseqüentemente a amostra do briquete produzido com $25 \%$ de RRSU apresentou maior poder calorífico superior; no entanto se observa que ela difere estatisticamente apenas do briquete produzido com 5\% de RRSU (Tabela 4).

O PCS da madeira e da celulose é semelhante e por outro lado o PCS médio dos termoplásticos é $74,17 \%$ maior que o PCS médio da madeira. Como os briquetes não serão comercializados com (zero)\% de umidade, o poder calorífico útil deve ser obtido e considerado parâmetro, uma vez que envolva a produção de energia.

Tabela 4. Poder calorífico superior, inferior e útil dos briquetes

\begin{tabular}{|c|c|c|c|c|c|}
\hline $\begin{array}{l}\% \text { de } \\
\text { Madeira }\end{array}$ & $\begin{array}{l}\% \text { de } \\
\text { RRSU }\end{array}$ & $\% \mathrm{H}$ & PCS $(\mathbf{k J ~ k g - 1 )}$ & $\mathrm{PCl}\left(\mathrm{kJ} \mathrm{kg}^{-1}\right)$ & $\mathrm{PCU}(\mathrm{kJ} \mathrm{kg-1)}$ \\
\hline 100 & 0 & 6,23 & 19544,20 a & 18135,68 a & 15657,94 a \\
\hline 95 & 5 & 6,58 & 19717,66 a & $18230,00 a b$ & $15740,96 a b$ \\
\hline 90 & 10 & 6,23 & $20197,39 a b$ & $18788,87 \mathrm{ab}$ & $16358,35 \mathrm{ab}$ \\
\hline 85 & 15 & 6,42 & $20599,83 a b$ & $19148,35 a b$ & $16549,10 a b$ \\
\hline 80 & 20 & 6,20 & $20623,99 a b$ & $19222,24 a b$ & $16614,13 a b$ \\
\hline 75 & 25 & 6,10 & $21239,13 \mathrm{~b}$ & $19860,00 \mathrm{~b}$ & $17175,35 \mathrm{~b}$ \\
\hline \multicolumn{3}{|c|}{ 100\% Celulose } & 19312,76 & & \\
\hline \multicolumn{3}{|c|}{ 100\% Termoplásticos } & 34039,68 & & \\
\hline
\end{tabular}

* Médias seguidas de letras iguais na mesma coluna não diferem pelo teste de Tukey

Tal como ocorreu com o PCS, o PCI foi crescente sempre que aumentou a porcentagem de RRSU adicionada ao briquete. Em relação ao briquete $100 \%$ madeira, a adição de RRSU trouxe vantagens do ponto de vista energético.

\section{CONCLUSÕES}

1. Os resultados experimentais mostraram que a adição de RRSU favorece o incremento do poder calorífico do briquete.

2. A briquetagem das misturas mostrou-se insatisfatória para os briquetes com $5 \%$ e $10 \%$ de RRSU pois, além de obterem as menores taxas de energia, mostraram-se quebradiços e com baixa resistência.

3. Os briquetes com porcentagem de RRSU acima de $15 \%$ tiveram um aumento de aproximadamente $43 \%$ sobre o teor de cinzas; observa-se, daí, a necessidade de se conhecer a procedência desse rejeito.

4. O briquete que apresentou maior energia utilizável foi o com $25 \%$ de RRSU.

5. Indica-se, portanto, a produção de briquetes com adição de RRSU, mas se deve ressaltar a necessidade de estudos sobre os componentes das cinzas e a emissão de gases provenientes da combustão dos briquetes.

\section{LITERATURA CITADA}

Acioli, J. L. Fontes de energia. Brasília: UnB, 1994. 138p.

Brito, J. O. Madeira para a floresta: A verdadeira realidade do uso de recursos florestais. Silvicultura, v.11, n.41, p.188-193, 1986.

Brito, J. O. Expressão da produção florestal em unidades energéticas. In Congresso Florestal Panamericano, 1, Congresso Florestal Brasileiro, 7, 1993, Curitiba, Anais...Curitiba: Sociedade Brasileira de Silvicultura, 1993, p.280-282.

Calderoni, S. Os bilhões perdidos no lixo. São Paulo: Humanitas, 1997, 343p.

CEMPRE - Compromisso Empresarial para Reciclagem. São Paulo. http://www.cempre.org.br. 5 Set. 2005.

Doat, J. Le pouvoior clorifique dês bois tropicaux. Revista Bois Forêsts Tropicaux, n.172, p.33-48, 1977.

Farinhaque, R. Influência da umidade no poder calorífico da madeira de bracatinga (Mimosa scrabella, Benth) e aspectos gerais de combustão. Curitiba: FUPEF, 1981. 14p. Série Técnica

Gomes, P. A . Teoria da carbonização da madeira, In: Uso da madeira para fins energéticos, Belo Horizonte: CETEC, v.1, 1980. p.27-42.

Gripp, W. G. Aspectos técnicos e ambientais da incineração de resíduos sólidos urbanos: Considerações sobre a proposta para São Paulo. São Carlos: EESC/ USP, 1998. 208p

Jardim, N. S.; Wells C. Lixo municipal - Manual de gerenciamento integrado. São Paulo: IPT/CEMPRE, 1995. 59p.

Kanayama, P. H. Minimização de resíduos sólidos urbanos e conservação de energia. São Paulo: Escola Politécnica da Universidade de São Paulo. 1999. 115p. Dissertação Mestrado

Pereira Júnior, V. B. Alternativas para a co-geração de energia de uma indústria de chapas de fibra de madeira, Energia na Agricultura, v.17, n.1, p.34-37, 2001.

Quirino, W. F. Características e índice de combustão de briquetes de carvão vegetal. Piracicaba: ESALQ, 1991. 64p. Dissertação Mestrado

Sartori M. M. P.; Florentino, H. O.; Basta, C.; Leão, A. L. Determination of the optimal quantity of crop residues for energy in sugarcane crop management using linear programming in variety selection and planting strategy. Energy, v.26, p.1031-1040, 2001.

Sartori M. M. P.; Leão, A. L. Caracterização da biomassa residual de colheita de cana-de-açúcar e seu potencial energético, em diferentes variedades e cortes. Energia na Agricultura, v.17, n.1, 84-87, 2002.

Tillman, D. A.; Rossi, A.; Vick, K. M. Incineration of municipal and hazardous solid wastes. New York: Academic Press, 1989.184p.

Vale, A. T. do; Brasil, M. A. M.; Carvalho, C. M. de; Veiga, R. A. de A. Produção de energia do fuste de Eucalyptus grandis Hill Ex-Maiden e acacia mangium Willd em diferentes níveis de adubação, Revista Cerne, v.6, n.1, p.83-88, 2000. 